\title{
PESQUISA EDUCACIONAL: DA CONSISTÊNCIA EPISTEMOLÓGICA AO COMPROMISSO ÉTICO
}

\author{
INVESTIGACIÓN EDUCATIVA: DE CONSISTENCIA EPISTEMOLÓGICA A \\ COMPROMISO ÉTICO
}

\author{
EDUCATIONAL RESEARCH: FROM EPISTEMOLOGICAL CONSISTENCY TO \\ ETHICAL COMMITMENT
}

Antônio Joaquim SEVERINO1

RESUMO: Construindo-se de uma perspectiva filosófica, o ensaio explicita as exigências epistêmicas e éticas que se põem como condições fundantes da prática da pesquisa, defendendo a igual relevância dessas duas perspectivas na construção do conhecimento científico, em geral, e da investigação específica no campo educacional, em particular. Ao abordar a pesquisa educacional, argumenta que, dada a natureza da educação como prática intencionalizada, como práxis, tanto no âmbito epistemológico como no âmbito ético, essas exigências se tornam ainda mais agudizadas, à vista do envolvimento radical com o destino existencial histórico das pessoas. Tal condição impõe ao pesquisador do campo educacional acurado rigor epistemológico em seu procedimento investigativo e compromissada sensibilidade ética à dignidade humana.

PALAVRAS-CHAVE: Pesquisa científica. Epistemologia da pesquisa educacional. Ética na prática da pesquisa. Ética na pesquisa educacional.

RESUMEN: Construyendo desde una perspectiva filosófica, el ensayo explica los requisitos epistémicos y éticos que se establecen como las condiciones fundacionales de la práctica de investigación, defendiendo la misma re-levancia de estas dos perspectivas en la construcción de conocimientos científicos, En general, y la investigación específica en el ámbito educativo, en particular. Al abordar la investigación educativa, argumenta que, dada la naturaleza de la educación como práctica intencionalizada, como praxis, tanto en el ámbito epistemológico como en el ético, estas demandas se agudiza aún más, habida cuenta de la implicación radical con la Destino existencial histórico de la gente. Esta condición impone al investigador el rigor epistemológico preciso del campo educativo en su procedimiento de investigación y ha comprometido la sensibilidad ética a la dignidad humana.

PALABRAS CLAVE: Investigación científica. Epistemología de la investigación educativa. Ética en la práctica de la investigación. Ética en la investigación educativa.

\footnotetext{
${ }^{1}$ Universidade Nove de Julho (UNINOVE), São Paulo - SP - Brasil. Docente do Programa de Pós-graduação em Educação. Professor titular, aposentado, de Filosofia da Educação na Faculdade de Educação da USP, ora atuando como docente colaborador. LATTES: http://lattes.cnpq.br/4415326563786783. ORCID: http://orcid.org/0000-00027922-9021. E-mail: ajsev@uol.com.br
}

RIAEE - Revista Ibero-Americana de Estudos em Educação, Araraquara, v. 14, n. 3, p. 900-916, jul./set., 2019. E-ISSN: 1982-5587. DOI: 10.21723 /riaee.v14i3.12445 
ABSTRACT: Constructing from a philosophical perspective, the essay explicitly explains the epistemic and ethical requirements that stand as fundamental conditions for the practice of research, defending the equal relevance of these two perspectives in the construction of scientific knowledge in general, and of specific research in the educational field, in particular. Addressing educational research, it argues that, given the nature of education as an intentional practice, as a praxis both in the epistemological and ethical spheres, these demands become even more acute in view of the radical involvement with people's historical existential destiny. Such condition imposes to the researcher of the educational field accurate epistemological rigor in its investigative procedure and committed ethical sensitivity to the human dignity.

KEYWORDS: Scientific research. Educational research epistemology. Ethics in research practice. Ethics in educational research.

\section{Introdução}

Em que pese a existência de múltiplos problemas postos pelo desenvolvimento tecnológico implementado pela ciência, não há como negar a grande contribuição que ela deu para agregação de qualidade à vida humana. Graças à ciência e à tecnologia dela decorrente, os homens puderam encontrar meios para melhor conduzir sua existência histórica, viabilizando disponibilidade e acessibilidade a todos recursos materiais e simbólicos de que precisam para aprimorar suas condições de sobrevivência. Como não reconhecer isso com a potencialização da produção de alimentos, da identificação e tratamento de doenças, da descoberta de medicamentos, da melhoria das condições de habitação, de locomoção, de transportes, bem como da viabilização da produção e da fruição dos bens culturais. Portanto, o papel da ciência é indiscutível para a construção da civilização, para a superação das determinações que condicionam e aprisionam o homem em sua relação com a natureza física pré-humana. $\mathrm{O}$ conhecimento em geral e o conhecimento científico em particular representaram conquistas altamente significativas no desenvolvimento da espécie, uma conquista inquestionável.

Reconhecida esta importância sociocultural a ciência como instância valiosa na contemporaneidade, impõe-se ter bem claras as implicações de sua construção, o que nos leva à prática da pesquisa, fonte de todo conhecimento científico. Daí a pertinência e a necessidade de refletirmos sobre todos os seus aspectos e procedimentos.

Duas perspectivas são imprescindíveis em se tratando da prática científica e devem ser levadas em conta. De um lado, seu arcabouço epistêmico, uma vez que se trata de um processo de conhecimento; de outro lado, as implicações de cunho ético nela envolvidos, eis que os resultados da ciência impactam necessariamente todas as condições de existência das pessoas.

RIAEE - Revista Ibero-Americana de Estudos em Educação, Araraquara, v. 14, n. 3, p. 900-916, jul./set., 2019. E-ISSN: 1982-5587. 
O objetivo deste breve ensaio, de cunho filosófico, é exatamente abordar essas duas exigências intrínsecas à prática científica no campo específico da educação: a consistência epistemológica do procedimento cognitivo posto em operação e a postura ética que precisa ser assumida pelo pesquisador da educação na sua prática investigativa. Como mediação privilegiada de construção do conhecimento científico dos fenômenos educativos, a pesquisa no campo da educação é interpelada não só pelos requerimentos lógico-epistemológicos da ciência em geral, mas também por demandas éticas agudizadas, em decorrência de se tratar de um campo prático que envolve intensa e extensivamente a alteridade, a presença do outro. Tanto quanto imprescindível é o seguimento dos parâmetros lógico-epistêmicos, o compromisso com a sensibilidade ética é igualmente necessário, cobrando-se do pesquisador da área uma permanente atenção, levando-se em conta que os resultados de sua investigação interferem diretamente na existência concreta das pessoas. Ademais, trata-se de fenômenos humanos em elevado grau, não podendo as pessoas e suas condutas ser manipuladas como se fossem meras peças de bancada de um laboratório. Levando-se em conta a presença da realidade humana no procedimento investigativo, desde o início se coloca a questão da dignidade da pessoa, impondo, de modo agudizado, a exigência da sensibilidade ética. Eis que o sujeito humano, quando se torna objeto de investigação, se transforma num outro para o pesquisador. Essa afirmação da alteridade no próprio objeto de pesquisa, transmuta radicalmente a relação do pesquisador com o mesmo.

\section{Garantindo a consistência epistemológica na prática científica}

O exercício do conhecimento científico funda-se na nossa capacidade subjetiva de explicitar os significados dos objetos e situações que são dados a nossa experiência. Trata-se de um processo de caráter eminentemente subjetivo e, até onde se pode demonstrar, bastante próprio e exclusivo da espécie humana. Ao mesmo tempo que permite uma relação bem diferenciada frente ao conjunto dos objetos, esse processo se caracteriza também pela sua capacidade de ser auto reflexivo, ou seja, ele volta-se sobre si mesmo, como se visse seu próprio ato de ver, ao ver um objeto qualquer.

Por isso mesmo, o conhecimento também se pratica, em nossa cultura, como metaconhecimento, mediante aquelas abordagens teóricas, consideradas e consolidadas como epistemológicas. Trata-se então de uma reflexão sistemática sobre como proceder para que se pratique adequadamente o conhecimento. 
A tradição filosófica mostra que para que conhecimento científico ocorra são demandados elementos epistemológicos, metodológicos e técnicos. Do ponto de vista epistêmico, impõe-se que a apreensão dos dados da realidade se dê sempre assegurando uma consistência cognitiva racional em todas suas relações de expressividade. É por isso mesmo que a linguagem privilegiada da ciência se aproxima prioritariamente da linguagem matemática.

Mas o proceder científico pressupõe igualmente que sigamos um caminho sistemático, disciplinado, ou seja, aplicando um método. Isto significa um disciplinamento da atividade investigativa que possa nos acautelar das ciladas da imaginação e da fantasia. Cabe ao método traçar um caminho que nos garanta o acesso aos fenômenos respeitando a objetividade e a autonomia dos dados ao mesmo tempo que a lucidez da subjetividade que se expressa então como racionalidade lógica,

\begin{abstract}
Mas a aplicação do método envolve ainda recurso a instrumentos técnicos, exatamente pela sua valiosa contribuição na apreensão mais objetiva dos dados de nossa experiência. Por exemplo, verificar a temperatura de um corpo pelo termômetro é mais garantido do que senti-la mediante o contato de nossas mãos. Medir uma distância com a trena é mais seguro do que por um golpe de vista (SEVERINO, 2016, p. 106-111).
\end{abstract}

\title{
O compromisso ético na prática científica
}

Já quanto à premissa referente à sensibilidade ética, está em pauta a demanda do compromisso ético intrinsecamente exigido dos pesquisadores. Com efeito, a reflexão sobre a dimensão ética na prática científica tem se intensificado nas últimas décadas em decorrência do aumento das más condutas de pesquisadores em todos os espaços institucionais que se dedicam a desenvolver investigações nos mais diferentes campos de conhecimento. Tais fatos têm preocupado cientistas e entidades responsáveis pela produção científica e pela aplicação das tecnologias dela derivadas, o que tem resultado na publicação de muitos estudos sobre a questão e na elaboração de códigos de ética e de protocolos de boas condutas na pesquisa científica. (FAPESP, 2014; 2018; MARQUES, 2018; NÓVOA, 2017; SANTOS, 2017; ALISSON, 2014; ESCOBAR, 2019; CNPq, 2011; CAPES, 2011; ABC, 2019). De modo particular, tem sido intenso e extenso o esforço por se desenvolver o estudo e a normatização relacionados à ética no caso da pesquisa com seres humanos, esforço fortemente incentivado, no Brasil, graças à aprovação das Resoluções 196, 466, 510, do Conep (BRASIL, 1996; 2012; 2016; SEVERINO, 2014; 2015; AMARAL FILHO, 2017; VON ZUBEN 2000; FORPRED, 2013). No que concerne especificamente à pesquisa educacional, também se tem desenvolvido um inves- 
timento sistemático, a Anped à frente, no sentido de se discutir a fundo e estabelecer parâmetros para a pesquisa na área (ANPED, 2018; MAINARDES, 2017; FARE; MACHADO; CARVALHO, 2014), iniciativa à qual voltarei mais adiante.

Como em todas as atividades humanas, também a prática da pesquisa científica é profundamente interpelada pelas exigências especificamente éticas, em todos os seus aspectos, modalidades e momentos. Daí a pertinência, a relevância e a necessidade da explicitação reflexiva da demanda da sensibilidade ética do pesquisador. De fato, a problemática ética impregna capilarmente nossa existência cotidiana com a mesma intensidade que a problemática epistêmica, eis que todas as expressões concretas de nosso existir estão sempre inelutavelmente envolvidas tanto com uma significação conceitual e quanto com uma apreciação valorativa. Não há como escapar. Tal situação é marca constitutiva da condição humana. Em tudo que fazemos, estão sempre envolvidos algum saber bem como alguma valoração. Isso decorre fundamentalmente da condição de entes dotados de uma dimensão de radical subjetividade, que nos coloca frente aos objetos de nossa experiência. Tanto quanto a racionalidade pensante, a sensibilidade ética ocupa lugar igualmente central no território da subjetividade humana. Do ato mais simples ao mais complexo, um equacionamento subjetivo simultaneamente conceitual e valorativo perpassa sua realização concreta.

Mas, cabe indagar: o que funda essa sensibilidade ética? Ela nasce da posição da presença dos outros de nós, da força da alteridade. Pois é essa presença que gera a demanda de seu reconhecimento como tal, impondo a cada um levar em conta a dignidade de que também os outros são igualmente portadores. Vale dizer que o fundamento de toda eticidade, bem como sua universalidade, decorrem da presença da alteridade, portadora de dignidade própria da pessoa humana.

Mas quem são os outros? Não são entidades abstratas e ideais; muito pelo contrário, manifestam-se fortemente concretizados e estão presentes ao nosso lado, sempre ao alcance de nossas relações, se espraiando em círculos concêntricos que nos rodeiam, círculos que vão desde a relação de contato físico próximo até uma esfera mais ampla de contato difuso, mais invisível, desde o grupo familiar, até o todo da humanidade, passando pelos grupos sociais constituídos em decorrência das múltiplas relações que os homens estabelecem entre si em função do trabalho, do lazer, da cidadania e de tantos outros interesses que podem se tornar comuns, nas variadas circunstâncias da vida histórica, mesmo quando essas relações não são imediatas e diretas. É por isso que, na esfera mais ampla da espécie humana, também estamos todos vinculados e unidos por uma solidariedade de destino. 
$\mathrm{Na}$ complexidade das situações reais, muitas vezes, todas estas situações se sobrepõem, de tal modo que os sujeitos as vivenciam simultaneamente, gerando implicações para suas opções. Mas, isoladas ou interligadas, em todas essas situações, está suposta uma esfera comum de significação do ético. É esse núcleo comum que define a eticidade das ações humanas. E para que se possa falar de uma referência ética, duas condições são postas como que a priori: a primeira, a presença da alteridade, a presença do outro; a segunda, o reconhecimento da dignidade da pessoa humana. Assim a ética envolve, de forma dialética, a presença de um eu frente a um outro. Ao mesmo tempo que ela supõe uma postura radical da subjetividade mais íntima do próprio eu, ela supõe, com igual necessidade, a objetividade do outro que coloca em frente do eu a sua alteridade (SEVERINO, 2014, p. 203-204).

Há que se registrar ainda que a presença intensa e extensa da alteridade expande a interação entre as pessoas, dando-lhe uma dimensão eminentemente social. O reconhecimento da alteridade e o respeito pela dignidade das pessoas dos outros ampliam igualmente a perspectiva da ética, fazendo dela uma dimensão ético-política.

É por isso mesmo que a necessária consideração da presença do outro, como condição de qualquer eticidade, faz com que os sentidos filosóficos de ética e de política se entrelacem intimamente. Trata-se de uma vinculação intrínseca e íntima. Não há como distinguir a qualidade ética de uma ação de sua qualidade política. A presença do outro em toda e qualquer circunstância da ação moral faz com que toda ação envolva necessariamente as duas dimensões ao mesmo tempo, a ética e a política. Embora no discurso corrente, é comum usar separadamente os conceitos, toda ação humana, sob a perspectiva moral, é ético-política. O uso separado dos conceitos e dos termos visa apenas enfatizar o aspecto mais pessoal, quando se usa o termo ético, e o aspecto mais social, quando se usa o termo político.

Mas o que torna vívido o vínculo que se estabelece entre as pessoas no contexto gerado pela presença da alteridade? O que nos leva a reconhecer e respeitar o outro? É o compartilhamento da mesma dignidade. É essa dignidade que funda e fundamenta toda a hierarquia dos valores, ela é a base de toda valoração, é ela que encarna e legitima nossa sensibilidade ética, sempre relacionada à presença do outro. Falar de sensibilidade e de compromisso éticos é fundamentalmente reconhecer e respeitar a dignidade do outro. É nela que se referencia a consciência moral que se impõe a nossa conduta, a nossa prática. Assim, o valor fundante dos valores que fundam a moralidade é aquele representado pela própria dignidade da pessoa humana, ou seja, os valores éticos fundam-se no valor da existência humana. É em função da qualidade desse existir, delineado pelas características que lhe são próprias, que se pode traçar o quadro da referência valorativa, para se definir o sentido do agir humano, individual ou co- 
letivo. Ou seja, o próprio homem já é um valor em si, nas suas condições de existência, na sua radical historicidade, facticidade, corporeidade, incompletude e finitude, enfim, na sua contingência. Não há onde buscar outro fundamento fora dele mesmo (SEVERINO, 2014, p. 206).

Note-se que à luz do entendimento filosófico, a dignidade humana é um valor e não uma essência descritiva de sua realidade concreta, em decorrência da qual o homem é um ser natural como todos os demais seres do planeta. Sua diferenciação vem da capacidade de se configurar como portador de uma qualificação valorativa e não meramente conceitual. Os homens se atribuem então um índice qualitativo de valoração que os torna merecedores de respeito, todos os indivíduos da espécie tornando-se sujeitos de dignidade, a qual não pode ser agredida e violentada. As exigências éticas decorrem, em última análise, do necessário respeito a essa dignidade.

Essa sensibilidade à dimensão ética, vivenciada por todos os humanos, se expressa em todos os espaços em que sua vida se desenrola. Não se dá apenas na dimensão filosófica, sob inquietações solitárias de estudiosos isolados. Ganha ressonância nos mais variados lugares culturais e institucionais, produzindo repercussões e induzindo medidas que causam impacto na vida cotidiana das comunidades, pois o que está em jogo afeta todas as pessoas, sem exceção. Invade até as esferas do senso comum. Por isso, ela se faz bem presente no seio da prática científica, destacando-se e ganhando nuances peculiares no caso da educação, em geral, e muito particularmente no caso da pesquisa educacional.

No que concerne à prática científica em geral, o questionamento ético, se coloca em três grandes esferas que, embora parecendo distintas, vistas assim de três ângulos específicos, na verdade, são íntima e intrinsecamente complementares e interligadas. Em todas elas, está em pauta, em última instância, o respeito à dignidade humana das pessoas nelas envolvidas.

De um primeiro ponto de vista, podemos considerá-la em sua interface com o macrossocial, quando estão em pauta iniciativas que envolvem sociedades e estados. Nesse caso, estamos diante de tomadas de decisão e de práticas bem abrangentes, atingindo toda a humanidade. Como exemplos, pode-se citar, além das guerras, situações como aquelas decorrentes do desenvolvimento e de aplicação de tecnologias que trazem ou podem trazer ameaças e danos para as sociedades humanas: os casos da utilização da energia nuclear, das armas químicas e biológicas, as pesquisas genéticas, as pesquisas ambientais. De forma que não predar ou poluir o ambiente natural, não maltratar os seres vivos tornam-se imperativos de valor ético, gerando cobrança por políticas públicas e de normas que coíbam tais ações e punam os infratores. Peter Singer elenca o cuidado com o ambiente e o tratamento atroz que é dado aos ani- 
mais como dois graves desafios éticos da humanidade nos dias atuais. Esta é uma perspectiva em que a ética assume uma conotação eminentemente política. (SINGER, 2013, p. 12-13). O compromisso cobrado do indivíduo decorre do compromisso mais amplo que ele tem com a sociedade em seu conjunto, com a polis.

De um segundo ângulo, podemos considerar aquelas situações internas a grupos mais restritos, quando comportamentos de pessoas, isolada ou coletivamente, ferem direitos e dignidade de outras pessoas ou grupos. Por exemplo, na manipulação desonesta de recursos comuns, na exploração dos mais fragilizados, na apropriação indébita de resultados e de esforços de outros. Estamos aqui diante de situações mais objetivadas para a prevenção das quais se criaram os códigos de ética, que se empenham em descrever e traduzir, mediante normas de direito positivo, os procedimentos considerados inadequados, eticamente condenáveis e juridicamente penalizáveis. Embora mais localizadas em espaços menores, estas situações também envolvem o ético com o político, num círculo menos abrangente.

Mas o pesquisador se envolve ainda numa situação mais subjetivada, que depende mais intensamente de sua opção e atitude pessoais. É quando, com suas decisões e ações pessoais, possa estar ferindo direitos de terceiros, quando atinge outras pessoas individuais, fraudando, no microcosmo de sua prática, determinados princípios éticos. Aqui está em questão o agir pessoal de cada um, visto no seu impacto sobre as outras pessoas com as quais se relaciona.

\section{Desafios epistemológicos da pesquisa educacional}

Em se tratando da pesquisa educacional, estas exigências epistemológicas e éticas se agudizam ainda mais. Isso porque do ponto de vista epistemológico, a construção do conhecimento científico no campo da educação se torna ainda mais difícil dado o fato de que sua fenomenalidade se constitui fundamentalmente marcada pela praxidade histórica. $\mathrm{O}$ fato de os fenômenos educativos serem fenômenos práticos intencionalizados dificulta em muito a percepção de sua objetividade e, consequentemente também sua determinação natural. Eles se encontram em permanente processo de transformação criativa, decorrente da intervenção dos sujeitos, não havendo como assegurar-lhes qualquer previsibilidade (SEVERINO, 2012, p. 99-114; GATTI, 2002). 
Daí o compromisso maior do pesquisador em educação de se empenhar para conduzir com rigor epistêmico a sua investigação, levando em conta a especificidade que a postura científica precisa assumir ao pesquisar os fenômenos educacionais.

Os fenômenos educacionais não podem ser abordados e tratados como objetos que se destrincham na bancada de um laboratório como se fossem peças de anatomia. Tal diferença decorre do fato de se tratar de uma prática histórico-social. Daí a exigência de uma modalidade epistêmica para deles se aproximar. Com efeito, conhecer, fazer ciência na esfera dos fenômenos educacionais, é diferente não apenas do fazer ciência no âmbito das ciências naturais, mas igualmente daquele que se desenvolve no âmbito das ciências humanas. Por isso mesmo, cabe fazer a distinção entre ciências da educação e uma possível ciência da educação. Uma coisa é buscar conhecer a fenomenalidade envolvida na dimensão antropológicoexistencial, com as perspectivas e recursos teórico-metodológicos das ciências humanas; outra coisa será compreender a especificidade da própria educação, mediante recursos epistemológicos específicos, que deem conta dessa condição original da educação como prática humana permanentemente em devir.

Mas, em que pese essa marcante peculiaridade, o desafio continua sendo o de se praticar o conhecimento seguindo os critérios gerais da cientificidade. Não está em pauta abrir mão dos parâmetros da ciência, entendidos como exigências de rigor, de metodicidade, de sistematicidade e de busca de universalidade, embora todos estes critérios devam ser assumidos levando-se em conta as características específicas do objeto educação, substantivamente prática histórico-social. Certamente, isso demanda uma cuidadosa revisão das pretensões exclusivistas do paradigma pressuposto na aplicação do método positivista da tradição científica de perfil newtoniano. E a razão fundamental dessa exigência é o caráter práxico da educação, ou seja, o fato de ser ela uma prática intencionada. Sua existência, sua realidade, sua substancialidade se constituem exatamente por essa condição de ser uma ação de intervenção social que constrói os sujeitos humanos. E isso com base numa intencionalidade, apoiando-se em significações que não são da ordem da fenomenalidade empírica dessa existência, não podendo, pois, a abordagem e explicitação desse sentido ser viáveis pelos caminhos epistemológico-metodológicos do processo epistêmico comumente chamado de ciência.

Sem dúvida, os sujeitos humanos envolvidos no processo educacional, são seres empíricos, entidades naturais e sociais, entes históricos, determinados por condições objetivas de existência, perfeitamente cognoscíveis pela via da ciência. Mas, ao agirem, esses sujeitos interagem permanentemente com essas condições, modificando-as pela sua práxis. Nesse sentido, como sujeitos, formam-se historicamente, ao mesmo tempo que vão formando, igualmente de 
modo histórico, os objetos de suas relações. Mas as supostas leis que presidiriam o desenvolvimento histórico não se situam mais nem no plano da determinação metafísica, nem no plano da necessidade físico-biológica. Em decorrência disso, a educação passa a ser proposta como processo, individual e coletivo, de constituição da realidade histórica da humanidade. Como se vê, o que está em pauta é a profunda historicidade humana (SEVERINO, 2012, p. 112).

Mas, se estas perspectivações afastam um reducionismo metodológico de jaez positivista, elas não endossam as pretensões das teorias fundadas num suposto paradigma da transdisciplinaridade do conhecimento, que pudesse ater-se tão somente à espontaneidade dos sentimentos, confundindo-se a economia do desejo com a economia da razão. Sem dúvida, a racionalidade lógica não esgota, de modo algum, a integralidade do território da subjetividade humana, mas a razão ocupa nele lugar fundamental na construção do conhecimento científico. Tanto é assim que a ciência da educação não dispensa a contribuição interdisciplinar das ciências humanas da educação. Como já afirmei em texto anterior,

A pesquisa em educação deve manter próximas e levar em rigorosa consideração, as conclusões das pesquisas das diversas áreas. Não se trata de refazer as pesquisas feitas por historiadores, sociólogos, economistas, antropólogos, etnólogos e psicólogos da educação (SEVERINO, 2012, p. 115).

Isto seria uma postura equivocada. Mas não se pode dar conta do caráter históricosocial da prática educacional desconhecendo-se os resultados explicitadores de seu sentido obtidos pela pesquisa científica realizada pelas ciências positivas da educação.

Assim como as peculiaridades do fenômeno educacional exigem critérios epistemológicos com alguma característica própria, para além daquelas básicas de todo procedimento científico, fica evidente que também a prática educativa impõe exigências éticas com marcas diferenciais bem acentuadas. Exigência essa que decorre do caráter intencional da prática educativa, uma vez que ela interfere muito diretamente sobre as outras pessoas, acontecendo no seio marcado pela própria realidade da alteridade. Seu objetivo é a própria humanização (SEVERINO, 2006). É sob essa significação que deve ser entendida e praticada toda mediação de nossa existência histórica, como o é o caso exemplar da educação bem como de todas as demais práticas humanas a ela relacionadas como a ciência e a pesquisa.

\section{Implicações éticas da pesquisa em educação}

Como referido anteriormente, a Anped, entidade mais representativa, no Brasil, do conjunto de pesquisadores na área, se propôs um programa integralmente dedicado a temati- 
zar essa problemática em suas discussões com vistas a estabelecer não só mecanismos procedimentais para a revisão ética mas também a construir uma fundamentação filosófica dos mesmos, a ser levada em conta inclusive na formação dos pesquisadores. Como a educação lida tão intensa e extensamente com o destino das pessoas, ela fica diretamente questionada da perspectiva ética, razão pela qual a pesquisa em seu campo encontra-se profundamente interpelada por essa exigência. Por isso mesmo, a ANPED vem investindo de maneira sistemática na busca de parâmetros para lidar com a prática investigativa, também sob essa perspectiva, no que acompanha as outras entidades que se dedicam à pesquisa envolvendo seres humanos, que já estabeleceram referências normativas e funcionais para essa atividade. Como informa Mainardes,

a maior parte dos desafios da área da educação é compartilhada com outros campos que envolvem as Ciências Humanas e Sociais, devido ao fato de que, no Brasil, há uma regulamentação única da ética em pesquisa com seres humanos para as duas grandes áreas (biomédica e CHS). Esse fato traz inúmeras dificuldades para a pesquisa em CHS, apesar das constantes críticas de pesquisadores e associações científicas dessa área (MAINARDES, 2017, 160).

O programa de trabalho, em desenvolvimento nos últimos anos, pretende alcançar um significativo espectro de objetivos com a finalidade de manter fecunda essa discussão:

Fomentar o debate sobre questões éticas na pesquisa em educação no âmbito da Anped (Comitê Científico, GTs da Anped, Forpred, PPGEs, Fepae e outros). - Articular ações sobre as questões da ética na pesquisa, na pósgraduação e nas publicações científicas da área de educação. • Assessorar a diretoria da Anped nas questões relacionadas à ética na pesquisa. • Ampliar o diálogo sobre questões éticas com as demais associações científicas do campo das Ciências Humanas e Sociais. • Propor políticas de apoio à pesquisa, a publicações e à realização de eventos e debates sobre a ética em educação. A ética na pesquisa em educação • Acompanhar e participar das discussões sobre a regulamentação da ética na pesquisa. - Manter atualizadas as informações sobre ética na pesquisa no Portal da Anped (MAINARDES, 2017, p. 162-163).

Mas esses objetivos se situam no seio de uma expectativa bem mais abrangente que envolve o caráter propriamente formativo desse cuidado ético na prática da pesquisa:

Para além das preocupações com as normas e procedimentos da revisão ética, considera-se essencial conceber a ética na pesquisa como uma questão de formação, que envolve o estudo e a discussão da ética na pesquisa na graduação e na pós-graduação (princípios e procedimentos). Observa-se, também, a importância da realização de pesquisas sobre ética na pesquisa, bem como a necessidade de ampliar as publicações sobre esse tema, incluindo a abordagem de questões cruciais da ética da pesquisa, a partir da prática da pes-

RIAEE - Revista Ibero-Americana de Estudos em Educação, Araraquara, v. 14, n. 3, p. 900-916, jul./set., 2019. E-ISSN: 1982-5587. 
quisa e dos dilemas enfrentados pelos pesquisadores (MAINARDES, 2017, p. 167).

Desses estudos e discussão ocorridos nos últimos anos, já resultou um Documento Preliminar que se encontra no Portal da ANPED, cuja intenção

[...] "é sistematizar a discussão que a área de Educação tem acumulado nos últimos anos sobre a ética na pesquisa, provocada principalmente pelo debate em torno dos dilemas do atual sistema de revisão ética existente no Brasil". [...] "de modo a dar continuidade à construção de um posicionamento da área sobre temas cruciais relacionados não apenas com o processo técnicoformal de revisão ética, mas também com os parâmetros da conduta ética da pesquisa em Educação que, a nosso ver, implicam considerações estéticas e políticas. Após o debate em todos os âmbitos da Anped pretende-se elaborar um documento de referência para a área que contenha os principais consensos sobre os parâmetros éticos da pesquisa em Educação" (ANPED, 2018).

De acordo com dois estudiosos da questão da ética na pesquisa educacional,

Pesquisas vêm mostrando que o mundo acadêmico não pode ficar apenas dentro da academia, até mesmo por questões éticas com seus objetos de pesquisa, seja ele o corpo docente, discente, administrativo, ou qualquer outro que permeie a educação. Assim, o cientista social ao deparar-se com seu "objeto", precisa desenvolver uma atitude ética retorno como forma não de agradecer pela ajuda em sua pesquisa, mas também para acrescentar àquele que serviu de objeto de pesquisa. Portanto, nesse movimento de ir e vir, produzir conhecimento científico e dar significado a ele não só é obrigação do pesquisador como também desejo do pesquisado, seja através de aproximações conceituais, de modo a compreender o objeto ou mesmo um diálogo que acrescente algo na sua prática (SANTOS; LOUREIRO, 2018, p. 2).

\section{Considerações finais}

Nunca é demais repetir que a finalidade da educação é a humanização, a formação das pessoas humanas, e mais do que qualquer outra prática social, cabe a ela, nessa condição, investir na construção da autonomia das pessoas, respeitando e consolidando sua dignidade. Trata-se da própria construção do ser humano que não é dado como pronto e acabado, mas como um ser a ser construído, num processo permanente de um vir-a-ser, de um tornar-se humano. Pois ao emergir na superfície da biosfera, o homem é um ser totalmente imanente numa infraestrutura existencial que o prende por fortes amarras a uma série de a prioris existenciais, intrínsecos às pulsões da vida. Mas o processo de construção do humano, a humanização, não é um processo linear e harmonioso. Ele é conflituoso em decorrência da caminhada que tem de ser conjunta com o outro, que pode tornar-se uma ameaça para a própria identidade do eu em construção. É o conflito e o confronto das diferenças, ameaça contínua a toda 
identidade. A educação se situa no emaranhado seio desse conflito permanente. (SEVERINO, 2012)

Esses princípios éticos gerais, todos fundados no necessário respeito à dignidade humana, no caso da pesquisa educacional, se fazem muito concretos, uma vez que tal campo envolve a abordagem dos sujeitos mediante procedimentos técnicos, como coleta de dados e informações pessoais, entrevistas, questionários, depoimentos, impondo-se então que estes procedimentos sejam aplicados com todos os cuidados para se garantir a privacidade e a intimidade dessas pessoas. Por isso, a pesquisa deve efetivar-se com o pleno consentimento, "livre e esclarecido" dos participantes ou de seus responsáveis. Igualmente na divulgação dos resultados, impõe-se assegurar a preservação da identidade e da integridade dos sujeitos. Não enganar os participantes, sob nenhuma forma, registrando-se quaisquer informes sob anonimato ou sob nomes fictícios. Na pesquisa educacional, a relação do pesquisador com os sujeitos pesquisados precisa estabelecer-se com total respeito a esses, inclusive dando-lhes acesso, mediante um efetivo retorno, a todos os resultados obtidos com a investigação realizada.

O cuidado ético não é uma exigência apenas das intervenções do ensino e da extensão, mas igualmente da pesquisa, porque a ciência não é mesmo decorrente apenas de uma prática puramente técnica e inocente (FORPRED, 2013, p. 4). Mas tanto quanto a sensibilidade ética, o rigor epistemológico é outro inelutável desafio para o pesquisador da área educacional.

Concluo retomando formulação de Ricoeur (1995), quando expressa a vivência ética: "viver bem com e para os outros em instituições justas", vivência que se daria implicando três exigências: a sensibilidade ética pessoal, a moralidade e o julgamento, ou seja, a sensibilidade do sujeito pessoal aos valores fundados na dignidade da condição de pessoa autônoma; a presença e a interação com o outro, o dado da alteridade, em que o outro se coloca como igualmente sujeito pessoal dotado de igual dignidade; a objetividade das circunstâncias da vida e a necessidade das instâncias institucionais como região e garantia das normas da convivência com outros, numa relação de justiça, e, finalmente, a necessidade e a capacidade de todos de formularem um juízo moral situado.

Mas caberia acrescentar aí uma quarta exigência. É preciso ainda que possamos viver num ambiente natural saudável, resultante da preservação do planeta, Singer (2014). É como se houvesse ainda a necessidade de um termo de convivência dos homens, não só com seus semelhantes, sob a égide de um contrato social (ROUSSEAU, 1997) mas também com natureza física, sob a égide de um contrato natural (SERRES, 1997), (MORIN 1991, 1994). 


\section{REFERÊNCIAS}

ACADEMIA BRASILEIRA DE CIÊNCIAS. Rigor e integridade na condução da pesquisa científica. Guia de Recomendações de Práticas Responsáveis. 2013. Disponível em: www.abc.org.bre/IM/pdf/doc-4559.pdf. Acesso em: 02 jan. 2019.

ALISSON, E. Má conduta científica é um problema global, afirma pesquisador. Revista Pesquisa Fapesp, Edição ago., 2014.

AMARAL FILHO, F. S. Ética e pesquisa nas Ciências Humanas e Sociais: um caso a ser pensado. Práxis Educativa, Ponta Grossa, v. 12, n. 1, p. 257-266, jan./abr., 2017.

ANPED. Associação Nacional de Pesquisa e Pós-graduação em Educação. Comissão de Ética. Ética na pesquisa em Educação. Rio de Janeiro: Anped, 2018. Disponível em:

http://www.anped.org.br/sites/default/files/etica_e_pesquisa_em_educacao_texto_para_discus sao_1.pdf. Acesso em: 10 jan. 2019.

BRASIL. Ministério da Saúde. Conselho Nacional de Saúde. Resolução nº196, 10 de outubro de 1996. Aprova as diretrizes e normas regulamentadoras de pesquisas envolvendo seres humanos. Diário Oficial da União, Brasília, DF, 10 out. 1996.

BRASIL. Ministério da Saúde. Conselho Nacional de Saúde. Resolução nº 466, de 12 de dezembro de 2012. Diário Oficial da União, Poder Executivo, Brasília, DF, 13 jun. 2013. Seção 1, n. 112, p. 59-62.

BRASIL. Conselho Nacional de Saúde. Resolução n ${ }^{\circ}$ 510, de 7 de abril de 2016. Diário Oficial da União, Poder Executivo, Brasília, DF, 24 maio 2016. Seção 1, n. 98, p. 44-46.

CAPES. Orientações Capes: combate ao plágio. Brasília: Capes, 2011.

CNPq. Ética e integridade na prática científica. Brasília: CNPq, 2011. Disponível em: http://www.cnpq.br/documents/10157/a8927840-2b8f-43b9-8962-5a2ccfa74dda.

ESCOBAR, H. Aumento de fraudes em pesquisas preocupa cientistas no mundo todo. O Estado de S. Paulo, Disponível em: https://www.estadao.com.br/noticias/geral,aumento-defraudes-em-pesquisas-preocupa-cientistas-no-mundo-todo-imp-,1012525. Acesso em: 11 jan. 2019.

FAPESP. Armadilhas que geram casos de má conduta. Revista Pesquisa Fapesp. Edição 268. jan 2018.

FAPESP. Código das Boas Práticas Científicas. 2014. Disponível em: www.fapesp.br/boas práticas/. Acesso em: 12 fev. 2019.

FARE, M.; MACHADO, F. V.; CARVALHO, I. C. de M. Breve revisão sobre regulação da ética em pesquisa: subsídios para pensar a pesquisa em educação no Brasil. Práxis Educativa. Ponta Grossa, v. 9, n. 1, p. 247-283, jan./jun., 2014.

FORPRED. Breve síntese do Seminário sobre Ética na Pesquisa em Educação. Promovido pelo Forpred Sudeste e PPG Educação/Unicamp. Campinas: Unicamp, 2013.

RIAEE - Revista Ibero-Americana de Estudos em Educação, Araraquara, v. 14, n. 3, p. 900-916, jul./set., 2019. E-ISSN: 1982-5587. 
GATTI, B. A. A construção da pesquisa em educação no Brasil. Brasília: Liberlivro, 2002.

MAINARDES, J. A ética na pesquisa em educação: panorama e desafios pós-Resolução CNS nº 510/2016. Educação (Porto Alegre), v. 40, n. 2, p. 160-173, maio-ago. 2017

MARQUES, F. O hábito de cometer fraudes: Pesquisadores japoneses se destacam em lista de cientistas com maior número de artigos retratados. Revista Pesquisa Fapesp. p. 8-10, out. 2018.

MORIN, E. O método. A natureza da natureza. Publicações Europa-América, 1991. v. 1.

MORIN, E.; KERN, A. B. Terra Pátria. Porto Alegre: Sulina, 1996.

NOVOA, A. Em busca da liberdade nas universidades: para que serve a investigação em educação? Revista Lusófona de Educação. Lisboa, no.28, p. 11-21, 2017.

RICOEUR, P. Da metafísica à moral. Lisboa: Instituto Piaget, 1995.

ROUSSEAU, J. Do contrato social. Ensaio sobre a origem das línguas. São Paulo: Nova Cultural, 1997. (Coleção Os Pensadores).

SANTOS, L. H. L. dos. Sobre a integridade ética da pesquisa. Ciência e Cultura, vol. 69 no. 3, jul./set, 2017.

SANTOS, R. B.; LOUREIRO, A. P. F. Ética em pesquisas na educação: quebrando barreiras. II CONEDU. Campina Grande-PB, 2015. Disponível em http://www.editorarealize.com.br/revistas/conedu/trabalhos/TRABALHO_EV045_MD4_SA3 _ID6473_16082015005541.pdf. Acesso em: 12 fev. 2019.

SERRES, M. O contrato natural. Lisboa: Instituto Piaget, 1994.

SEVERINO, A. J. A busca do sentido da formação humana: tarefa da Filosofia da Educação. Educação e Pesquisa, v. 32, n. 3, p. 619-634, 2006.

SEVERINO, A. J. Educação, sujeito e história. 3 ed. São Paulo: Olho d’Água, 2012.

SEVERINO, A. J. Dimensão ética da investigação científica. Revista Práxis Educativa, UEPG, Ponta Grossa. Vol. 9, N 1, p. 199-208, 2014.

SEVERINO, A. J. Ética e pesquisa: autonomia e heteronomia na prática científica. Cadernos de Pesquisa. São Paulo: Fundação Carlos Chagas, v. 45 p.776-791, 2015.

SINGER, P. O dever de evitar o mal. Jornal da USP. Ano 29, no. 1011. setembro de 2013.

VON ZUBEN, N. A. Bioética e tecnociências: A saga de Prometeu e a esperança paradoxal. Bauru: EDUSC, 2000. 


\section{Como citar este artigo:}

SEVERINO, Antônio Joaquim. Pesquisa educacional: da consistência epistemológica ao compromisso ético. Revista Ibero-Americana de Estudos em Educação, Araraquara, v. 14, n. 3, p. 900-916, jul./set., 2019. E-ISSN: 1982-5587. DOI: 10.21723/riaee.v14i3.12445

Data de Submissão: 27/02/2019

Aceite em: 15/03/2019

Publicado em: 23/03/2019 